\title{
Early growth response- $I$ is a regulator of DR5-induced apoptosis in colon cancer cells
}

\author{
D Mahalingam ',2, A Natoni', M Keane ${ }^{3}$, A Samali' and E Szegezdi, ${ }^{*}$, \\ 'Cell Stress and Apoptosis Research Group, Department of Biochemistry and National Centre of Biomedical Engineering Science, National University of \\ Ireland, Galway, Ireland; ' ${ }^{2}$ Cancer Therapy and Research Center, University of Texas Health Science Center San Antonio, San Antonio, TX, USA; ${ }^{3}$ University \\ College Hospital, Galway, Ireland
}

BACKGROUND: Tumour necrosis factor-related apoptosis-inducing ligand (TRAIL) induces tumour cell apoptosis by binding to death receptor 4 (DR4) and DR5. DR4 and DR5 activation however can also induce inflammatory and pro-survival signalling. It is not known how these different cellular responses are regulated and what the individual role of DR4 vs DR5 is in these processes. METHODS: DNA microarray study was carried out to identify genes differentially expressed after DR4 and DR5 activation. RT-PCR and western blotting was used to examine the expression of early growth response gene-I (Egr-I) and the proteins of the TRAIL signalling pathway. The function of Egr-I was studied by siRNA-mediated knockdown and overexpression of a dominant-negative version of Egr-1.

RESULTS: We show that the immediate early gene, Egr- I, regulates TRAIL sensitivity. Egr-I is constitutively expressed in colon cancer cells and further induced upon activation of DR4 or DR5. Our results also show that DR4 mediates a type II, mitochondriondependent apoptotic pathway, whereas DR5 induces a mitochondrion-independent, type I apoptosis in HCTI5 colon carcinoma cells. Egr-I drives c-FLIP expression and the short splice variant of c-FLIP (c-FLIPS) specifically inhibits DR5 activation.

CONCLUSION: Selective knockdown of c-FLIPS sensitises cells to DR5-induced but not DR4-induced apoptosis and Egr-I exerts an effect as an inhibitor of the DR5-induced apoptotic pathway, possibly by regulating the expression of c-FLIPS.

British Journal of Cancer (2010) I 02, 754-764. doi:10.1038/sj.bjc.6605545 www.bjcancer.com

Published online 19 January 2010

(C) 2010 Cancer Research UK

Keywords: tumour necrosis factor-related apoptosis-inducing ligand (TRAIL); early growth response gene-I (Egr-I); death receptor 5 (DR5); type I extrinsic apoptotic pathway; cellular FLICE inhibitory protein (c-FLIP); colon carcinoma

Tumour necrosis factor-related apoptosis-inducing ligand (TRAIL) is a member of the TNF ligand superfamily (Ashkenazi and Dixit, 1998). It induces the extrinsic apoptotic pathway upon binding to its death domain (DD)-containing receptors, TRAIL receptor 1 (death receptor 4 (DR4)) and 2 (death receptor 5 (DR5)). Binding of TRAIL to DR4 and DR5 induces receptor oligomerisation, intracellular DD clustering and recruitment of the adaptor molecule Fas-associated death domain (FADD). The death effector domains (DEDs) of FADD then interact with the DED of pro-caspases 8 and 10 , leading to the formation of the deathinducing signaling complex (DISC). The DISC serves as a platform to oligomerise and activate pro-caspases 8 and 10 (Kischkel et al, 2000; Sprick et al, 2000). Active caspases 8 and 10 are released from the DISC and activate executioner caspases, caspases 3, 6 and 7 , committing the cell to death.

Active caspases 8 and 10 can also cleave and activate Bid, a $\mathrm{BH} 3$-only member of the Bcl-2 protein family. Truncated Bid then

\footnotetext{
*Correspondence: Dr E Szegezdi, Department of Biochemistry, National University of Ireland, University Road, Galway, Ireland; E-mail: Eva.Szegezdi@nuigalway.ie

Received I June 2009; revised 14 December 2009; accepted 17 December 2009; published online 19 January 2010
}

activates Bax and Bak to induce mitochondrial outer membrane permeabilisation and cytochrome $c$ release (Eskes et al, 2000; Green and Kroemer, 2004). In the cytosol, cytochrome $c$ binds to the WD40 domains of the adaptor protein, Apaf-1, which initiates the assembly of the heptameric apoptosome complex. Pro-caspase- 9 is recruited to the apoptosome and becomes activated (Green, 2000). Activation of the intrinsic apoptosis pathway in this manner serves to amplify the apoptotic signal and guarantees that the programme is irreversible.

In certain cells, which are classified as type I cells, the intrinsic apoptosis pathway is not required to commit the cell to apoptosis upon TRAIL receptor activation; however, in other cells, which are classified as type II cells, this amplification loop is essential. Overexpression of anti-apoptotic Bcl-2 proteins inhibits TRAIL-induced apoptosis in type II cells only (Fulda et al, 2002). Poor activation of pro-caspases 8 and 10 at the DISC is probably one of the major factors that account for the type II phenotype (Scaffidi et al, 1999). By competing with pro-caspase-8 for binding to FADD and inhibiting caspase-8 at the DISC, FLICE-inhibitory protein (c-FLIP) may be a key determinant of the type I $v s$ type II phenotype (Scaffidi et al, 1999; Barnhart et al, 2003).

Despite the high homology between DR4 and DR5 and the identical core DISC components recruited to DR4 and DR5, 
the two receptors are not equally involved in transducing the TRAIL-apoptotic signal (Ichikawa et al, 2001; Ashkenazi, 2002; Kelley et al, 2005; van der Sloot et al, 2006). In the colon cancer cell line, Colo205, we have shown that TRAIL induces apoptosis predominantly through DR5 (van der Sloot et al, 2006). Conversely, in the leukaemia cell lines, ML-1 and EM-2, DR4 is the predominant transducer of apoptosis (van Geelen et al, 2003; MacFarlane et al, 2005). So far, there is no clear explanation for the differential activity of DR4 and DR5. Two reports shed some light to possible, selective regulation of DR4 and DR5. These studies have shown that DcR2 selectively inhibited DR5, but not DR4, through a ligand-dependent or ligand-independent association with DR5 (Clancy et al, 2005; Merino et al, 2006). But what regulates DR4 function, or whether there are intracellular regulators specific to DR4 or DR5, is completely unknown.

In addition to caspase activation, DR4 and DR 5 can activate the transcription factors nuclear factor- $\kappa \mathrm{B}$ (NF- $\kappa \mathrm{B})$ and c-Jun, or protein kinases, such as Akt, mitogen-activated protein kinases (MAPKs) such as c-Jun NH2-terminal kinase (JNK) and extracellular signal-regulated kinase (ERK) (Falschlehner et al, 2007), which lead to the activation of multiple signal transduction pathways. To examine the role of these pathways in the regulation of DR4 or DR5 function, genes induced or repressed by recombinant human TRAIL (rhTRAIL) and DR5-selective rhTRAIL variants were determined in a colon cancer cell model using cDNA microarray technology. In this report we show that the immediate early gene, Egr-1, is constitutively expressed in colon cancer cells and further induced in response to rhTRAIL by both DR4 and DR5. Furthermore, we show that the short isoform of c-FLIP controls the activity of the DR5 receptor, but not of DR4. The constitutively expressed Egr-1 inhibits TRAILmediated apoptosis, probably by driving constitutive c-FLIP expression.

\section{MATERIALS AND METHODS}

\section{Cell culture and treatments}

Colo205 cells were obtained from American Tissue Culture Collection (ATCC). HCT15 and HCA7 cells were a kind gift from Professor L Egan (National University of Ireland, Galway). Colo205 and HCT15 cells were maintained in RPMI-1640 medium and HCA7 in DMEM medium, both media supplemented with $10 \%$ fetal bovine serum (FBS), $2 \mathrm{~mm}$ glutamine, $50 \mathrm{U} \mathrm{ml}^{-1}$ penicillin and $50 \mathrm{mg} \mathrm{ml}^{-1}$ streptomycin at $37^{\circ} \mathrm{C}, 5 \% \mathrm{CO}_{2}$ in a humidified incubator. Cells were seeded at $2 \times 10^{5}$ cells ml ${ }^{-1}$ at 1 day before treatment. To induce apoptosis, cells were treated with rhTRAIL (non-tagged, fragment of amino acids 114-281, Triskel Therapeutics, Groningen, The Netherlands) DR5-selective mutants D269H, D269H/E195R, agonistic DR4 or DR5 antibodies (Novartis Pharmaceuticals, Basel, Switzerland), recombinant human TNF (PromoCell, Heidelberg, Germany) or agonistic anti-Fas antibody (clone $\mathrm{CH}-11$, MBL International, Woburn, MA, USA) at the concentration and times specified in the figure legends. All reagents were from Sigma-Aldrich (St Louis, MD, USA) unless otherwise stated.

\section{Cell viability assay}

Cell viability was monitored using 3-(4, 5-dimethylthiazolyl)-2, 5-diphenyl tetrazolium bromide (MTT) assay. After treatment, MTT $\left(0.5 \mathrm{mg} \mathrm{ml}^{-1}\right)$ was added to cells and incubated for $3 \mathrm{~h}$ at $37^{\circ} \mathrm{C}$. The reaction was stopped by addition of an MTT stop solution of $20 \%$ SDS in $50 \%$ dimethyl formamide. The purple formazan precipitate generated was allowed to dissolve for $1 \mathrm{~h}$ on an orbital shaker. The colour intensity was measured at $550 \mathrm{~nm}$ on a Wallac Victor 1420 Multilabel counter (PerkinElmer Life
Sciences, Waltham, MA, USA). Cell viability was expressed relative to the absorbance of untreated cells, which was taken as $100 \%$ viable.

\section{Cell death assay}

Cell death was monitored by labelling of phosphatidyl serine externalised on the surface of apoptotic cells with Annexin-V-FITC (IQ Corporation, Groningen, The Netherlands) or by haematoxylin and eosin staining of cytospins. For Annexin V staining, cells were collected by gentle trypsinisation and incubated for $10 \mathrm{~min}$ at $37^{\circ} \mathrm{C}$ to allow membrane recovery. Cells were pelleted by centrifugation at $350 \mathrm{~g}$ and incubated with Annexin-V-FITC in calcium buffer (10 mM HEPES/NaOH, pH 7.4, $140 \mathrm{~mm} \mathrm{NaCl}$ and $2.5 \mathrm{mM} \mathrm{CaCl}_{2}$ ) for $15 \mathrm{~min}$ on ice in the dark. Cells were washed in calcium buffer before acquisition on a FacsCalibur flow cytometer (Becton Dickinson, Franklin Lakes, NJ, USA). Analysis was performed using Cell Quest software (Becton Dickinson). Haematoxyin - eosin staining has been carried out as described before (Szegezdi et al, 2008).

\section{Microarray analysis}

Global gene expression analysis was carried out on RNA prepared from Colo205 cells exposed to rhTRAIL, D269H or D269H/E195R for $1 \mathrm{~h}$. Microarray hybridisation and bioinformatics analysis was performed by ArraDx Array-Based Diagnostics using Affymetrix human HgU133 Plus 2.0 gene chips in triplicate (Belfast, UK). Single-channel experiments were carried out with all RNA samples labelled with biotin. In brief, double-stranded cDNA was synthesised from $5 \mu \mathrm{g}$ total RNA, and purified and biotin labelled. Labelled cRNA was fragmented, purified and quantified before its hybridisation to the gene chips for $16 \mathrm{~h}$ at $45^{\circ} \mathrm{C}$. The arrays were washed, stained with streptavidin-phycoerythrin solution for $10 \mathrm{~min}$ at $25^{\circ} \mathrm{C}$, and then re-washed and probed with a biotinylated antibody solution for $10 \mathrm{~min}$ at $25^{\circ} \mathrm{C}$. The streptavidin-phycoerythrin solution was added for a further $10 \mathrm{~min}$ and washed before scanning. The GeneSpring data analysis program (Silicon Genetics/Agilent, Santa Clara, CA, USA) was used for bioinformatical analysis. Fold increases or decreases induced were compiled for the treatments. Genes with greater than a two-fold change and a $t$-test $P$-value of $<0.05$ were considered differentially regulated.

\section{RNA isolation and RT-PCR}

Total RNA was isolated using GenElute RNA miniprep kit (SigmaAldrich) according to the manufacturer's protocol. Reverse transcription (RT) was carried out with $2 \mu \mathrm{g}$ RNA using oligo (dT) primers (Invitrogen, Carlsbad, CA, USA) and AMV reverse transcriptase. The cDNA product was subjected to $25-30$ cycles of PCR using primers specific for Egr-1, c-Jun, TEA domain family member 1 (TEAD-1), naked cuticle homologue 2 (NKD2), voltagedependent anion channel 3 (VDAC3), NF- $\kappa$ B inhibitor- $\alpha$ /inhibitor$\kappa \mathrm{B}-\alpha(\mathrm{NFKBIA} / \mathrm{I} \kappa \mathrm{B} \alpha)$ and NF- $\kappa$ light polypeptide gene enhancer in B-cells inhibitor- $\zeta(\mathrm{NFKBIZ} / \mathrm{I} \kappa \mathrm{B} \zeta)$. For normalisation, GAPDH

\begin{tabular}{|c|c|c|}
\hline $\begin{array}{l}\text { Gene } \\
\text { name }\end{array}$ & Reverse sequence & Forward sequence \\
\hline Egr-1 & 5'-AAGAACTTGGACATGGCTGTाT-3' & 5'-GAAAGAAAGGGAAAAGGCAGAA-3' \\
\hline c-jun & $5^{\prime}$-CCTGACCATAGCATCAAGTACA-3' & 5'-ACTCCCCTAACCTGTITCTGC-3' \\
\hline TEAD / & $5^{\prime}$-AACTTTGGTGGAACAGGTGACT-3' & 5'-CATTGCTTGAATCAGTGGACAT-3' \\
\hline VDAC3 & 5'-TAGACTTCAGTGTGGGAGGAT-3' & 5'-GGAAGCTTAATGTGGTाTGAGG-3' \\
\hline$N F \kappa B I A$ & 5'-TCCATCTTGAAGGCTACCAACT-3' & 5'-GCCCTGGTAGGTAACTCTGTTG-3' \\
\hline$N F \kappa B I Z$ & $5^{\prime}$-CTGTCTITGTGAATGCAAAGG-3' & 5'-GAGCTCGCTGCTGAATGGACTT-3' \\
\hline NKD2 & 5'-CGGCAGGTAGTAGCTGAAGG-3' & $5^{\prime}$-AGATACACATGCCGTACACCAC-3' \\
\hline GAPDH & $5^{\prime}$-TCCACCACCCTGTTGCTG-3' & $5^{\prime}$-ACCACAGTCCATGCCATC- $3^{\prime}$ \\
\hline
\end{tabular}


PCR was carried out. The primers used for the PCR reactions are listed below.

\section{Protein lysate preparation and western blot analysis}

Cells were lysed in buffer containing $100 \mathrm{~mm}$ Tris - $\mathrm{HCl}, \mathrm{pH} 8.0,1 \%$ Triton X-100, $200 \mathrm{~mm}$ sodium chloride $(\mathrm{NaCl}), 5 \mathrm{~mm}$ EDTA, $10 \%$ glycerol, $1 \mathrm{~mm}$ dithiothreitol (DTT), $1 \mathrm{~mm}$ phenylmethylsulphonyl fluoride (PMSF), $5 \mu \mathrm{g} \mathrm{ml}^{-1}$ aprotinin, $2.5 \mu \mathrm{g} \mathrm{ml}^{-1}$ leupeptin, $1 \mathrm{~mm}$ sodium orthovanadate $\left(\mathrm{Na}_{2} \mathrm{VO}_{3}\right)$ and $1 \mathrm{~mm}$ sodium fluoride $(\mathrm{NaF})$. Cellular proteins $(30 \mu \mathrm{g})$ were separated by electrophoresis on $8-10 \%$ SDS polyacrylamide gels and transferred onto nitrocellulose membranes. After blocking in 5\% non-fat milk and $0.05 \%$ Tween-20 in PBS, blots were incubated with rabbit antibodies to total Egr-1 (1:1000 dilution, Santa Cruz Biotechnologies, Santa Cruz, CA, USA), Mcl-1, Bax (1:1000, Cell Signaling Technology, Danvers, MA, USA) or mouse monoclonal antibodies to c-FLIP (1:500, Alexis Pharmaceuticals, Axxora UK Ltd., Nottingham, UK), Bcl-X $\mathrm{L}_{\mathrm{L}}$ (clone H-5, $1: 200$, Santa Cruz Biotechnologies), Bcl-2 (clone 100, 1:1000, Santa Cruz Biotechnologies) or X-linked inhibitor of apoptosis protein (XIAP; $1: 2000$, Assay Designs, Ann Arbon, MI, USA). For detection, appropriate horseradish peroxidase-conjugated goat secondary antibodies were used (Thermo Fisher Scientific, Rockford, IL, USA). Protein bands were visualised with SuperSignal West Pico Chemiluminescent Substrate (Pierce) on X-ray film (Agfa, Morstel, Belgium).

\section{Transfections and plasmids}

Dominant-negative Egr-1 construct (EBGN-EGR-1) expresses a truncated version of murine Egr-1 lacking the transactivational domain and containing only the zinc-finger DNA-binding site (amino acids 322-533) fused to GST. The empty vector, EBGN, contains a nuclear-expressed GST (Al-Sarraj et al, 2005); both these vectors are a kind gift from Professor G Thiel (University of Saarland Medical Center, Homburg, Germany). pEBS1 ${ }^{4}$ luc, an Egr-1 reporter construct, contains four copies of Egr-1 response element of the Egr-1 gene promoter in the pGL3-promoter vector (also a gift from Professor G Thiel, University of Saarland Medical Center) (Al-Sarraj et al, 2005). To normalise for transfection efficiency, a constitutive Renilla luciferase expressing plasmid was used (pRL-CMV, Promega Corporation, Madison, WI, USA). For transfection, HCT15 cells $\left(2 \times 10^{6}\right)$ were pelleted and resuspended in transfection solution V (Lonza Group Ltd., Basel, Switzerland) containing $2.5 \mu \mathrm{g}$ of plasmid unless otherwise stated. Transfection was performed by nucleofection using program T13 according to the manufacturer's protocol (Amaxa). GFP plasmid $(2.5 \mu \mathrm{g})$ was used to determine transfection efficiency, which was $48 \pm 7 \%$. Control cells were subjected to the same transfection condition without any plasmids. At $24 \mathrm{~h}$ after transfection, cells were resuspended in media and seeded for Annexin $\mathrm{V}$ and protein assays. Similarly, stable transfection of Bcl-2 or empty vector (Neo) was carried out in HCT15 cells using the same transfection protocol (a kind gift from Dr Peter Daniel, University of Berlin, Berlin, Germany). Pools of stable clones were selected with $1 \mu \mathrm{M}$ of G418. siRNA transfection was carried out by the same nucleofection protocol as for plasmids using 50-75 nM siRNA. The following c-FLIP sequences were targeted: c-FLIP ${ }_{\mathrm{S} / \mathrm{L} 1}: 5^{\prime}$-GGAGCAGGGAC AAGTTACA-3', c-FLIP ${ }_{\mathrm{S} / \mathrm{L} 2}$ : 5'-GCAAGGAGAAGAGTTTCTT-3', c-FLIP $_{\mathrm{S} / \mathrm{L} 3}: 5^{\prime}$-GAGGTAAGCTGTCTGTCGG-3' (Nakajima et al, 2008), c-FLIP S1 $_{1}: \quad 5^{\prime}$-CACCCTATGCCCATTGTCC- ${ }^{\prime}, \quad$ cFLIP $_{\mathrm{S} 2}$ : 5'-CATGGAACTGCCTCTACTT-3' (Zhang et al, 2004; Longley et al, 2006). The GFP target sequence was: 5'-GGCUACGUCCAG GAGCGCACC-3'. To knock down Egr-1, an siRNA Smartpool containing a mixture of four Egr-1-specific siRNAs was used (Dharmacon, Thermo Fisher Scientific, Rockford, IL, USA). Transfection was carried out as for c-FLIP siRNAs.

\section{Luciferase assay}

Luciferase activity was determined using the Dual Glo Luciferase assay system (Promega). The measurement was carried out according to the manufacturer's instructions.

\section{Cell surface expression of TRAIL receptors}

Cells were washed twice in PBS containing 1\% BSA and then incubated with monoclonal antibodies to DR4 or DR5 (Alexis) for 40 min. After two wash steps with PBS-BSA, anti-mouse IgG-FITC (Sigma) secondary antibody was added for $30 \mathrm{~min}$. All incubations were carried out on ice. Negative controls contained isotype control antibody. Cells were analysed using FacsCalibur flow cytometer.

\section{Statistical analysis}

Differences in Annexin V staining between the treatment groups were analysed using a non-paired Student's $t$-test, with a significance level of $P<0.05$. Error bars shown are s.e.m. All statistical analyses were performed using Graphpad Prism 4 (GraphPad Softward Inc, San Diego, CA, USA).

\section{RESULTS}

\section{Colon carcinoma cells are sensitive to rhTRAIL but use different receptors to transmit the death signal}

To determine the sensitivity of colon carcinomas to TRAILinduced apoptosis, Colo205 and HCT15 cell lines were treated with increasing concentrations of rhTRAIL or DR5-selective TRAIL variant, D269H/E195R for $3 \mathrm{~h}$ (Figure 1A) (van der Sloot et al, 2006). Colo205 cells were more sensitive to D269H/E195R than rhTRAIL, whereas in HCT15 cells rhTRAIL seemed to be a stronger inducer of death (Figure $1 \mathrm{~A}$ and $\mathrm{B}$ ).

To determine what TRAIL receptors transmitted the apoptotic signal, cells were treated with agonistic DR4- and DR5-selective antibodies (Novartis) for 3 and $5 \mathrm{~h}$, for Colo205 and HCT15 cells, respectively. In the absence of crosslinking of anti-DR4 and antiDR5 with a secondary antibody, the agonistic antibodies induced similar, low level of apoptosis in Colo205 cells. To more closely mimic the action of the trimeric TRAIL ligand on the receptors, the agonistic antibodies were crosslinked with a secondary antibody through their Fc regions. Crosslinking is likely to enhance clustering and thus the activation of the death receptors in a similar manner as it has recently been shown for Fas (Scott et al, 2009). Crosslinking significantly increased the activity of the DR5-agonistic antibody, but not of the DR4 antibody (Figure 1C), agreeing with previous reports showing that DR5, but not DR4, requires crosslinking for optimal activation (Kelley et al, 2005). In HCT15 cells, both the DR4 and DR5 antibodies induced apoptosis, with the DR4 antibody being a stronger death inducer. Again, enhanced apoptosis was observed after crosslinking of the DR5, but not the DR4-agonistic antibody (Figure 1D). These results show that in Colo205 cells, TRAIL signals apoptosis primarily through the DR5 receptor, whereas in HCT15 cells, the TRAIL death signal can be transmitted by both receptors.

\section{rhTRAIL induces Egr-1 through both DR4 and DR5}

To generate a profile of early response genes induced by TRAIL receptor activation, Colo205 cells were treated with either rhTRAIL or DR5-selective rhTRAIL variants (D269H and D269H/E195R) for $1 \mathrm{~h}$. Microarray analysis was carried out on Affymetrix human HgU133 Plus 2.0 GeneChips in triplicate. The concentration of TRAIL and DR5 variants was chosen to be $10 \mathrm{ng} \mathrm{ml}^{-1}$ as it induced near-maximal apoptosis in Colo205 cells (Figure 1A). By examining 

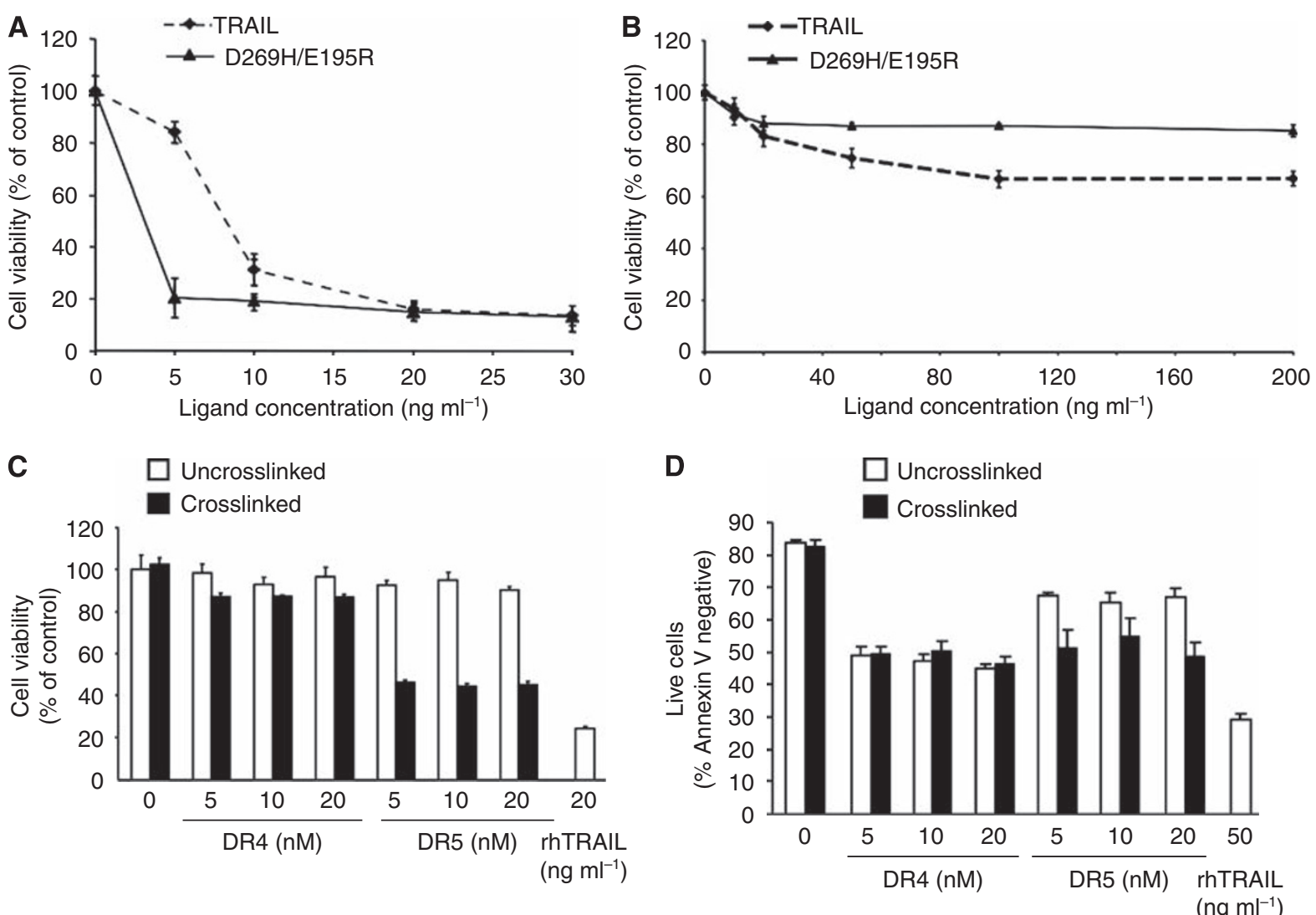

Figure I Colon carcinoma cells are sensitive to rhTRAIL with Colo205 cells responding to DR5 stimulation and HCTI5 to both DR4 and DR5. Cell viability of Colo205 (A) and HCTI5 (B) cells treated with WT rhTRAIL and DR5-selective TRAlL variant D269H/El95R (5-30 and I0-200 ng ml ${ }^{-1}$, respectively) for $24 \mathrm{~h}$. Cell viability was measured using MTT assay. Values are expressed as a percentage of untreated cells and presented as mean \pm s.e.m. of three independent experiments. Colo205 (C) and HCTI5 (D) cells were treated with 5-20 nM of agonistic DR4 (DR4) and DR5 antibodies (DR5) for 24 and $5 \mathrm{~h}$, respectively. Where indicated, agonistic antibodies were crosslinked using I5-60 nM of crosslinking antibody for 30 min before cell treatment. Cell death was measured using MTT assay in Colo205 cells and Annexin $\vee$ staining in HCTI 5 cells. The results are presented as mean \pm s.e.m. of three independent experiments.

the temporal induction of TRAIL-regulated genes known from the literature, such as BTG family 3 (BTG3), ubiquitin-specific protease 24 (USP24), KIAA0770 and cyclin T1 (CCNT1) upregulated by TRAIL and non-POU-domain containing octamer binding (NoNo), downregulated by TRAIL) (Kumar-Sinha et al, 2002), it was determined that gene expressional changes are detectable from $1 \mathrm{~h}$ of TRAIL treatment and thus this time point was chosen for the microarray analysis (Supplementary Figure 1).

The microarray analysis revealed 69 genes differentially expressed in response to at least one treatment. Cluster analysis identified four genes regulated by both TRAIL and DR5-selective variants. These were CDC42 effector protein 1 (CDC42EP1), Egr-1, TEAD1 and VDAC3. Functional clustering identified that the regulated genes have a role in intracellular transport, cellular proliferation, post-translational modification and transcriptiontranslation regulation (Table 1A). Of these genes, seven candidates were selected for further analysis based on proposed biological function and fold induction-repression by rhTRAIL (Table 1B). The full list of genes differentially expressed can be found in Supplementary Table 1. Except the induction of c-Jun, upregulation of Egr-1, NFKBIA/I $\kappa \mathrm{B} \alpha$ and NFKBIZ/I $\kappa \mathrm{B} \zeta$ and downregulation of Homo sapiens NKD2, VDAC3 and TEAD1 in Colo205 cells by rhTRAIL were all confirmed validating the microarray results (Figure 2A).

Egr-1, which is also known as NGFI-A, zif268, krox24 and Tis8, is a transcription factor implicated in tumour progression and apoptosis after diverse stimuli (Thiel and Cibelli, 2002). Currently, there is no information about its role in TRAIL-induced apoptosis.
Analysis of Egr-1 protein expression in colon carcinoma cell lines (Colo205, HCT15 and HCA7) showed high basal expression of Egr-1 and its further induction in response to rhTRAIL, DR4- and DR5-agonistic antibodies (Figure 2B and C). A double band of Egr-1 was detected in HCT15 and HCA7 cells. The upper band probably corresponds to a phosphorylated form of Egr-1, which has been shown to increase its activity (Beckmann and Wilce, 1997). For quantification, blots were also probed for $\beta$-actin and the densitometric ratio of Egr- 1 to $\beta$-actin was calculated (Figure $2 \mathrm{C}$ ).

\section{Overexpression of dominant-negative Egr-1 potentiates apoptosis induction by DR5}

To determine whether Egr-1 has any role in TRAIL-induced apoptosis, HCT15 cells were transiently transfected with a plasmid expressing dominant-negative Egr-1 (EBGN-Egr-1) that contains only the DNA-binding domain of Egr-1 fused to GST (Al-Sarraj et al, 2005). Overexpression of dominant-negative Egr-1 protein (DN-Egr-1) was confirmed by western blot analysis using Egr-1 antibody (inlet, Figure 3A). On the blot, the lower (approximately $56 \mathrm{kDa}$ ) band represents the truncated, DN-Egr-1. To inhibit Egr-1 activity, $2.5 \mu \mathrm{g}$ of DN-Egr-1 plasmid was transfected into the cells, as this amount was found to fully block Egr-1 transcriptional activity for at least $48 \mathrm{~h}$ after transfection (Supplementary Figure $2 \mathrm{~A})$. After $5 \mathrm{~h}$ treatment with $10 \mathrm{nM}$ agonistic DR5 antibody or rhTRAIL, HCT15 cells overexpressing DN-Egr-1 suffered significantly more apoptosis than untransfected cells or cells transfected with the empty vector (Figure $3 \mathrm{~A}$ ). Interestingly, no enhancement 
in apoptosis was observed in cells treated with agonistic DR4 antibody (Figure 3A). Knockdown of Egr-1 with siRNA (Smartpool, Dharmacon) also increased the sensitivity of HCT15 cells to DR5 activation, but not to DR4 activation (Figure 3B).

\section{Only DR4-induced, but not DR5-induced, apoptosis requires mitochondrial amplification in HCT15 cells}

As overexpression of DN-Egr-1 affected only the DR5-mediated but not the DR4-mediated apoptotic pathway, we wanted to determine whether DR5 and DR4 signal apoptosis through the same pathway in HCT15 cells. As Egr-1 has been reported to regulate the expression of Bcl-2 proteins (Huang et al, 1998b; Ahmed, 2004), first the requirement for mitochondrial amplification for DR4- and DR5-mediated apoptosis was assessed. To this end, stable, mitochondrial-targeted Bcl-2 overexpressing HCT15 cells were generated (mass pool of stable transfectants of Bcl-2ActA overexpressing cells; Figure 4A) and treated with agonistic DR4 and DR5 antibodies (10 $\mathrm{nM})$ or rhTRAIL $\left(50 \mathrm{ng} \mathrm{ml}^{-1}\right)$. Cells were treated for $12 \mathrm{~h}$ to allow all cells affected to undergo apoptosis. Bcl-2 overexpression reduced the level of apoptosis induced by DR4, but not by DR5 or rhTRAIL (Figure 4B), indicating that in HCT15 cells the DR4-induced apoptotic pathway requires mitochondrial amplification, whereas the DR5-induced pathway does not. The effect of DN-Egr-1 on the expression of key mitochondrial proteins was nonetheless examined. Western blot analysis showed that overexpression of DN-EGR-1 did not alter the expression levels of $\mathrm{Bax}, \mathrm{Bcl}-2, \mathrm{Bcl}-\mathrm{X}_{\mathrm{L}}, \mathrm{Mcl}-1$ or XIAP (Supplementary Figure 2B).

Table IA Functional clustering of TRAIL/DR5-variant regulated genes

\section{Function}

Vesicle and/or protein transport

Rho signalling

Post-translational protein modification

Transcription/translation

Transcription factors

Translational related

Cell proliferation/survival pathways

Ras pathway

PI3K pathway

Protein kinases/phosphatase

$N F-\kappa B$ inhibitor proteins

DNA/RNA helicases

Cancer related

Abbreviations: DR5 = death receptor $5 ; \mathrm{NF}-\kappa \mathrm{B}=$ nuclear factor $-\kappa \mathrm{B} ; \mathrm{TRAlL}=$ tumour necrosis factor-related apoptosis-inducing ligand.

\section{DN-Egr-1 overexpression reduces c-FLIP expression in HCT15 cells}

As the mitochondrial pathway is not required for DR5-mediated apoptosis in HCT15 cells, we next examined whether overexpression of DN-Egr-1 can modulate the expression of the components of the TRAIL-DISC: TRAIL receptors, pro-caspase- 8 and c-FLIP. DN-Egr-1 did not have any effect on the surface expression of any of the four TRAIL receptors or the expression of pro-caspase- 8 (Figure 5A and $\mathrm{B}$ ). On the other hand, overexpression of DN-Egr-1 decreased the expression of c-FLIP, especially of the short c-FLIP isoform (c-FLIP , Figure $5 \mathrm{~B}$ and $\mathrm{C}$ ). Knockdown of Egr-1 also reduced the expression of c-FLIP, and the reduction was more pronounced in the short c-FLIP splice variant (Supplementary Figure 3A and B). When the expression of Egr-1 and c-FLIP was studied in colon and breast cancer cell lines, we found that high Egr-1 expression often associates with high

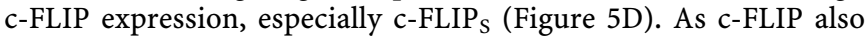
inhibits death signalling through the TNF receptor and Fas, the effect of DN-Egr-1 on TNF and Fas sensitivity of HCT15 cells was examined. We found that DN-Egr-1 increased apoptosis induced by both TNF and agonistic anti-Fas antibody (Supplementary Figure 3C).

By analysing the $5^{\prime}$ region of the human $c$-FLIP gene using the Transcription Element Search System web interface (Schug, 2008) (TESS, http://www.cbil.upenn.edu/cgi-bin/tess/tess?RQ = WELCOME), we found the 9 nucleotide Egr-1 binding site (GSG motif: CGGGGGCG) at the beginning of the first intron (Supplementary Figure 4). The binding sequence has a nearly $100 \%$ identity to the weighted matrix consensus sequence (Swirnoff and Milbrandt, 1995) (http://www. cbil.upenn.edu/cgi-bin/tess/tess?request $=$ IMD-DBRTRV-Accno\&key $=$ I00117), indicating that it is a high-affinity site for Egr-1 binding.

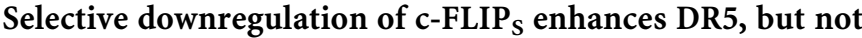 DR4-induced apoptosis in HCT5 cells}

siRNA oligonucletides targeting three regions of c-FLIP, common in c-FLIP $_{\mathrm{L}}$ and c-FLIP $_{\mathrm{S}}\left(\mathrm{c}-\mathrm{FLIP}_{\mathrm{L} / \mathrm{S} 1-3}\right)$ were designed and transfected into HCT15 cells. Downregulation of c-FLIP $\mathrm{L}_{\mathrm{L}}$ and c-FLIP $_{S}$ was confirmed using western blot analysis at $24 \mathrm{~h}$ after transfection (Figure 6A). The c-FLIP ${ }_{L / S}$ siRNA resulted in downregulation of both $\mathrm{c}-\mathrm{FLIP}_{\mathrm{L}}$ and c-FLIP $\mathrm{F}_{\mathrm{S}}$ HCT15 cells transfected with the siRNAs were treated with $50 \mathrm{ng} \mathrm{m}^{-1}$ rhTRAIL, $10 \mathrm{nM}$ crosslinked DR4 or DR5 antibodies for $5 \mathrm{~h}$ and induction of apoptosis was assessed. All treatments resulted in enhanced cell death in $c$-FLIP ${ }_{\mathrm{L} / \mathrm{S}}$ siRNA-transfected cells when compared with non-transfected or GFP siRNA-transfected cells (Figure 6B). In view of the greater downregulation of c-FLIPs than c-FLIP ${ }_{L}$ by DN Egr-1, we chose to specifically downregulate c-FLIPs. The only unique region of c-FLIP ${ }_{S}$ in comparison to $\mathrm{c}^{-F_{L}} \mathrm{P}_{\mathrm{L}}$ is the short exon 7 (Golks et al, 2005), which contained only two stretches of

Table IB TRAIL/DR5-variant regulated genes selected for validation

\begin{tabular}{|c|c|c|c|c|}
\hline \multirow[b]{2}{*}{ Genes } & \multicolumn{3}{|c|}{ Fold change } & \multirow[b]{2}{*}{ Biological function } \\
\hline & TRAIL & D269H & D269H/EI95R & \\
\hline Egr & 2.5 & 2.1 & 3.3 & Transcription factor \\
\hline c-jun & 1.2 & 1.6 & 2.0 & Transcription factor \\
\hline TEAD $/$ & -1.6 & -1.5 & -1.9 & Transcription factor \\
\hline VDAC3 & -1.5 & -1.9 & -2.0 & Voltage gated anion channel \\
\hline$N F \kappa B \mid A / / \kappa B \alpha$ & 1.3 & 1.6 & 2.1 & $N F-\kappa B$ inhibitor \\
\hline$N F \kappa B / Z / / \kappa B \zeta$ & 1.8 & 2.0 & 2.1 & $N F-\kappa B$ inhibitor \\
\hline NKD2 & -1.6 & -1.3 & -1.6 & $\mathrm{NF} \kappa \mathrm{B}$ inhibitor, negative regulator of WNT pathway \\
\hline
\end{tabular}

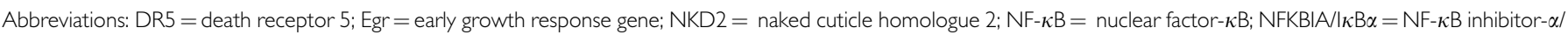
inhibitor- $\kappa$ B- $\alpha$; NFKBIZ/I $\kappa \mathrm{B} \zeta=\mathrm{NF}-\kappa$ light polypeptide gene enhancer in B-cells inhibitor- $\zeta$; TEAD-I = TEA domain family member I; TRAIL = tumour necrosis factor-related apoptosis-inducing ligand; VDAC3 = voltage-dependent anion channel 3. 
Egr-I regulates DR5-induced apoptosis via c-FLIP
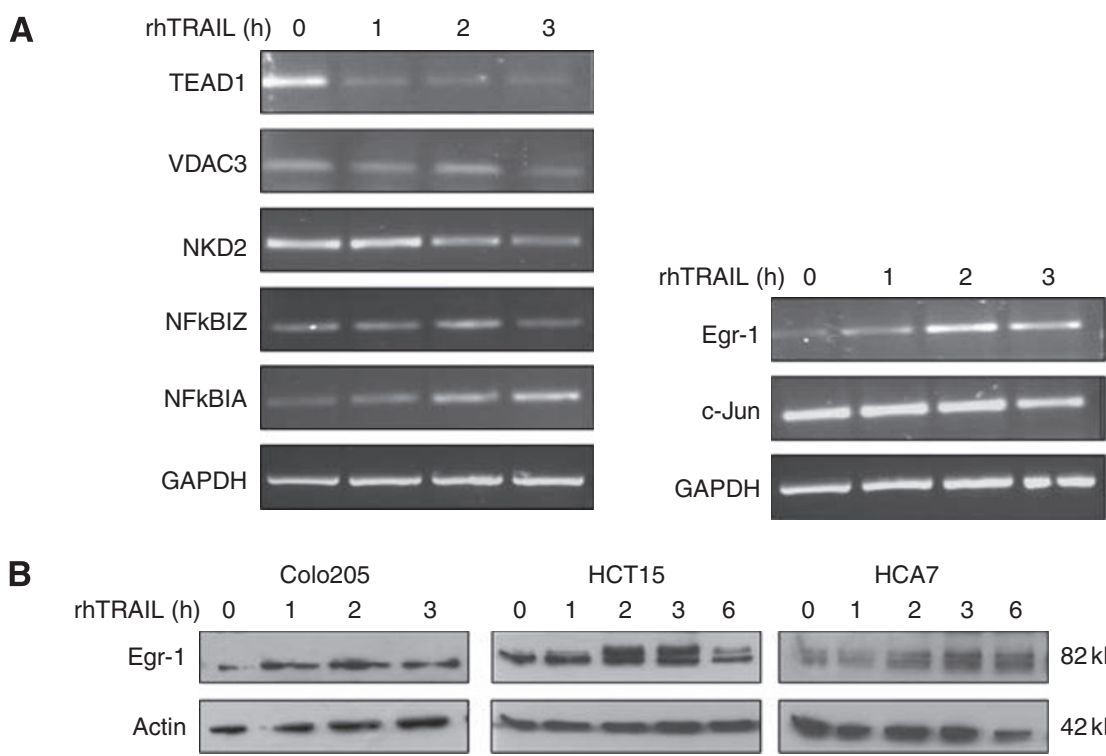

HCT15

236
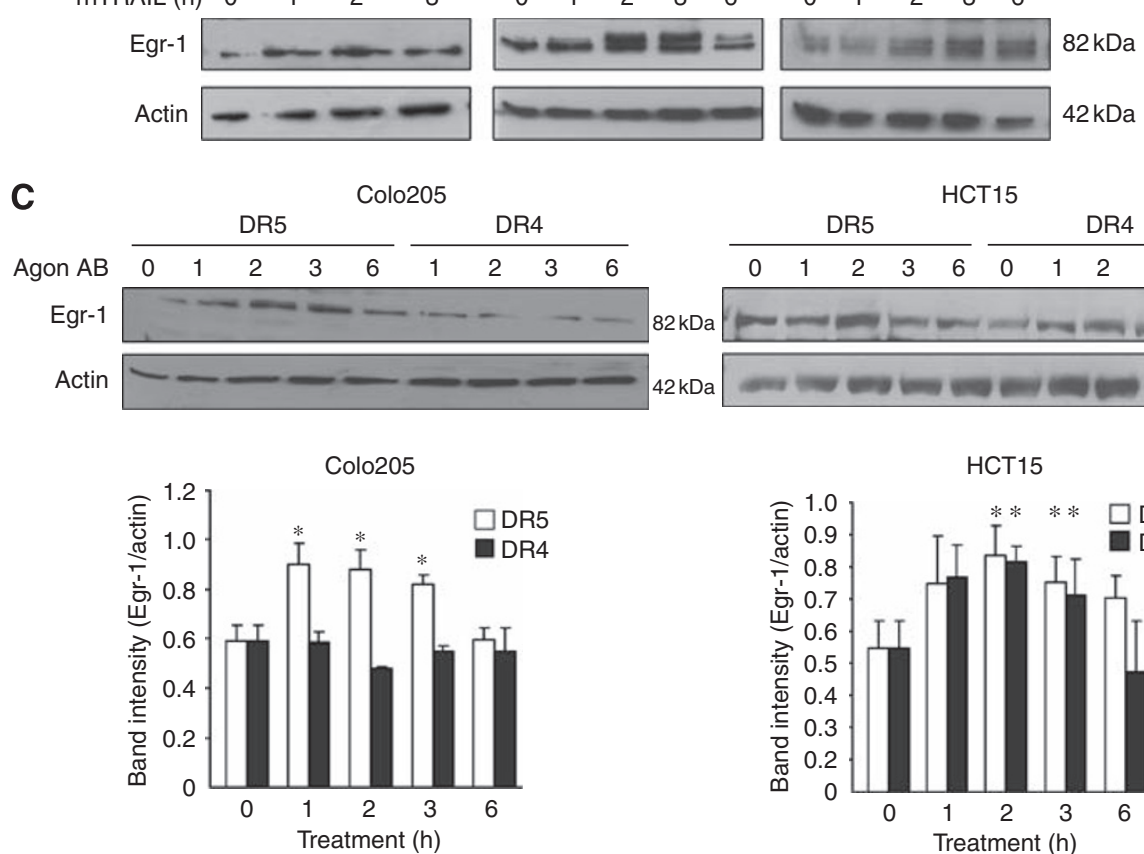

HCT15
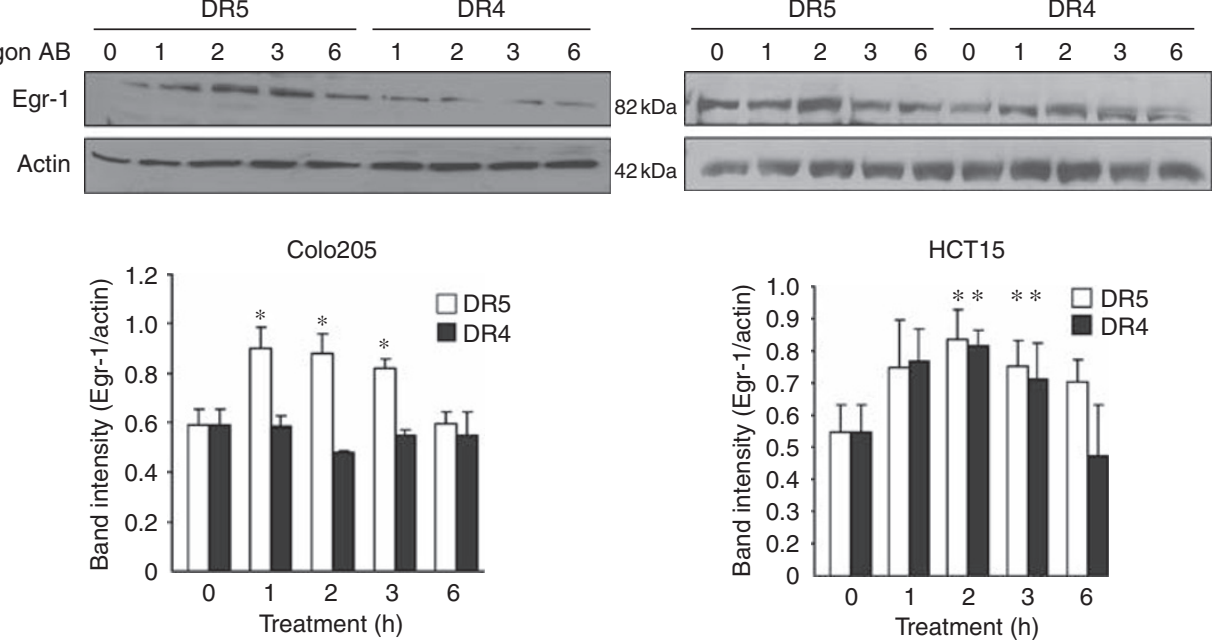

Figure 2 rhTRAIL induces Egr-I expression that can be mediated by both DR4 and DR5. (A) Validation of cDNA microarray results. Colo205 cells were treated with $10 \mathrm{ng} \mathrm{ml}^{-1}$ of WT rhTRAlL and total RNA was isolated at the times indicated. mRNA expression of TEADI, VDAC3, NKD2, Egr-I, c-Jun, NFKBIA and NFKBIZ were assessed using RT-PCR. GAPDH was used as internal control. The figure shows a representative image of three independent experiments. (B) Induction of Egr-I protein by TRAIL receptor activation. Colo205, HCTI5 and HCA7 cells were treated with rhTRAIL at a concentration of $10 \mathrm{ng} \mathrm{ml}^{-1}$ (Colo205) and $50 \mathrm{ng} \mathrm{ml}^{-1}$ (HCTI5 and HCA7). Cell lysates were prepared at the indicated times and analysed for the expression of Egr- I using western blotting. Actin expression was detected for loading control. The figure shows representative images of two independent experiments. (C) The role of DR4 and DR5 in Egr-I induction. Colo205 and HCTI 5 cells were treated with I 0 nM of crosslinked agonistic DR4 (DR4) and DR5 antibodies (DR5). Cells lysates were prepared at the indicated times and expression of Egr-I protein was analysed using western blotting. Detection of actin was used as a loading control. Densitometric quantification of Egr-I levels. The graph shows averaged Egr-I band densities normalised for total $\beta$-actin levels in the lysates. Results are presented as means \pm s.e.m. of three independent experiments; $* P<0.05$ comparing Egr-I induction at each time points to control.

sequences targetable with siRNA. Of these two siRNAs, however, only one (c-FLIP $\left.{ }_{\mathrm{S}-2}\right)$ was able to significantly downregulate c-FLIP expression, the c-FLIP $\mathrm{S}_{\mathrm{S}}$ siRNA targeting the first region $\left(\mathrm{c}-\mathrm{FLIP}_{\mathrm{S}-1}\right)$

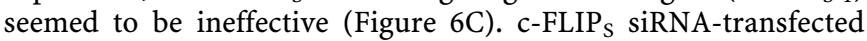
HCT15 cells were treated with WT rhTRAIL, DR4- or DR5agonistic antibodies and the apoptosis-potentiating effect of

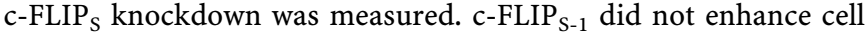
death in response to any of the treatments, as expected. However, c-FLIP $_{\mathrm{S}-2}$ siRNA-transfected cells showed increased cell death in response to WT rhTRAIL and DR5 antibody, but not to DR4 antibody; that is, c-FLIP $\mathrm{S}$ knockdown mirrored the effect of DN Egr-1 (Figure 6D).

\section{DISCUSSION}

Death ligands induce apoptosis in tumour cells (Ashkenazi and Dixit, 1998; Papenfuss et al, 2008) independent of p53 and thus offer an alternative therapy to genotoxic agents (Ashkenazi, 2008). Various formulations of DR agonists, TNF, Fas ligand and TRAIL are in phase I and II clinical trials with promising results (Papenfuss et al, 2008; Mahalingam et al, 2009). Of the death ligands, TRAIL is of special interest, as in contrast to TNF and FasL, it has minimal or no toxic side effects (Ashkenazi et al, 2008). However, the regulation of TRAIL-induced apoptosis, the mechanism of TRAIL resistance and the differential role of DR4 
A

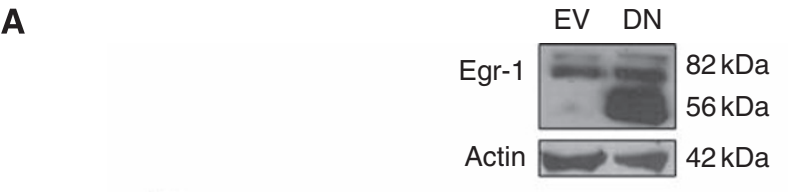

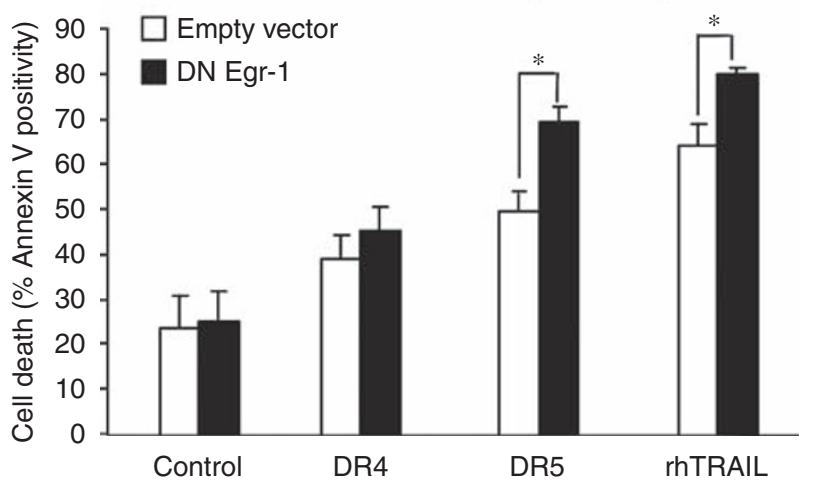

B
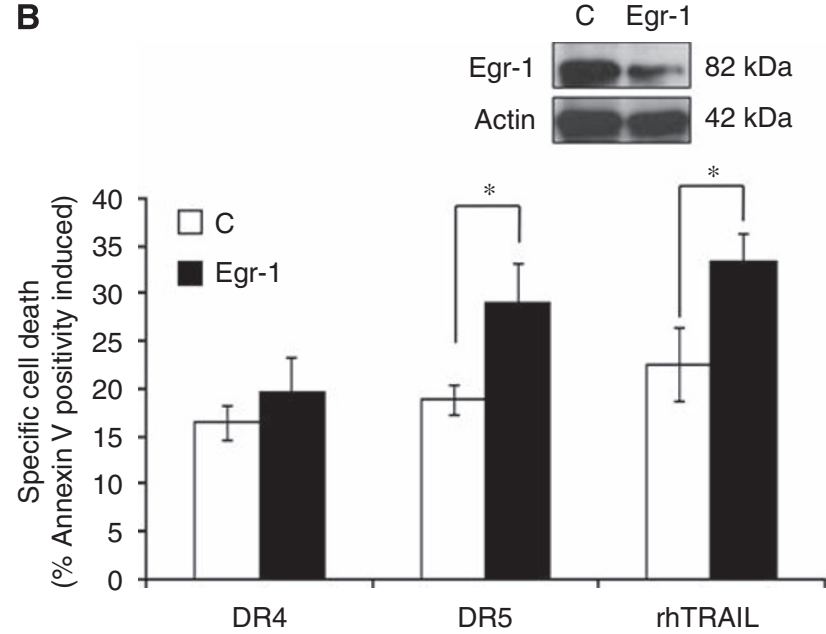

Figure 3 Inhibition or knockdown of Egr-I potentiates rhTRAIL- and DR5-induced apoptosis. (A) Effect of dominant-negative Egr-I (DN-Egr-I) expression on TRAIL-, DR4- and DR5-induced apoptosis in HCTI5 cells. HCTI 5 cells were transiently transfected with EBGN-Egr-I (DN) or empty vector (EV). Cell lysates of parental cells (C), EV- and DN-Egr- I-transfected cells were analysed for overexpression of DN-Egr-I at $24 \mathrm{~h}$ after transfection using western blotting (inlet). HCTI5 cells transfected with pEBGN-EGR-I (DN-Egr-I) were treated at $24 \mathrm{~h}$ after transfection with either $10 \mathrm{~nm}$ of crosslinked agonistic DR4/DR5 antibody or $50 \mathrm{ng} \mathrm{ml}^{-}$ rhTRAIL for $5 \mathrm{~h}$ and apoptosis was assessed using Annexin $\mathrm{V}$ staining (DR4, DR5 and rhTRAIL). (B) Knockdown of Egr-I sensitises HCTI5 cells to TRAIL and DR5-induced apoptosis. HCTI5 cells were transiently transfected with a Smartpool siRNA mix against Egr-I (Egr-I) or scrambled siRNA (control siRNA, C). Knockdown of Egr-I was confirmed $24 \mathrm{~h}$ after transfection using Western blotting (inlet). Cells were treated as described in point $(\mathbf{A})$ and induction of apoptosis was measured with Annexin $V$ staining. Results are presented as means \pm s.e.m. of at least three independent experiments; *Significant difference with $P<0.05$.

and DR5 in TRAIL signalling is not sufficiently understood (Di Pietro and Zauli, 2004; Duiker et al, 2006).

To gain insight into the regulation of TRAIL-induced apoptosis, we identified the early response genes regulated by TRAIL receptor activation. Gene ontological clustering identified regulation of gene transcription as one of the main biological functions regulated by TRAIL. Among the TRAIL-regulated transcription factors were TEAD1 and Egr-1. Egr-1 (also known as NGFI-A, zif268, krox24 and Tis8) is a zinc-finger transcriptional factor that belongs to a group of early response genes together with Egr-2,
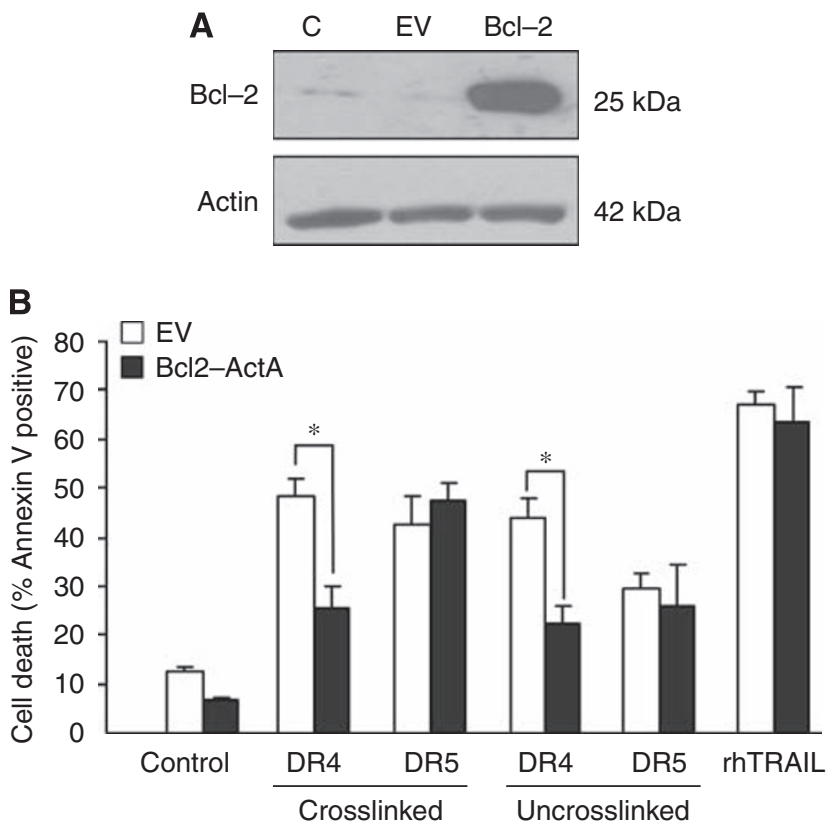

Figure 4 Only DR4-, but not DR5-mediated, apoptosis requires mitochondrial amplification in HCTI5 cells. (A) Overexpression of mitochondrial-localised $\mathrm{Bcl}-2$. HCTI 5 cells were stably transfected with mitochondrial-localised $\mathrm{Bcl}-2$ (Bcl-2-ActA: $\mathrm{Bcl}-2$ ) expressing plasmid or empty vector (EV). Overexpression of Blcl-2-ActA was confirmed using western blotting. (B) Bcl-2 ActA protects HCTI 5 cells from DR4-, but not from DR5- or rhTRAIL-induced apoptosis. Cells were treated with $10 \mathrm{nM}$ of crosslinked or uncrosslinked agonistic DR4 and DR5 antibodies or $50 \mathrm{ngml}^{-1}$ of rhTRAlL for $12 \mathrm{~h}$ and apoptosis was measured using Annexin $V$ staining (DR4, DR5, rhTRAIL labels). Results are presented as means \pm s.e.m. of three independent experiments. Asterisks (*) designate significant difference $(P<0.05)$ between the indicated sample pairs.

Egr-3, Egr-4, Egr- $\alpha$ and the tumour suppressor, Wilms' tumour gene product, WT1. Egr-1 has been implicated in the control of cell growth, survival and transformation (Thiel and Cibelli, 2002; Ahmed, 2004). Egr-1 has also been connected to the development of human cancers. It has been proposed to have a role in multistage carcinogenesis in the skin (Riggs et al, 2000). High levels of constitutive Egr-1 expression have been observed in most human prostate cancers and found to correlate with more advanced stages of malignancy and poor prognosis (Eid et al, 1998). Moreover, tumour progression in transgenic mouse models of prostate cancer was reported to be significantly impaired when Egr-1 was not expressed (Abdulkadir et al, 2001). Egr-1 basal expression was also found to be much higher in gastric cancer tissues than in normal gastric mucosa and high Egr-1 mRNA expression correlated with metastasis to lymph nodes and remote organs (Kobayashi et al, 2002).

To date, the studies analysing the functions of Egr-1 have been contradictory, with reports of both cytoprotective and proapoptotic functions in tumour cells (Huang et al, 1998a; Virolle et al, 2001). Egr-1 induction has been implicated as a key event in response to ionising radiation-induced growth arrest or cell death mediated by Egr-1 target genes such as TNF- $\alpha$, p53, Retinoblastoma and Bax (Ahmed, 2004). The role of Egr-1 in TRAIL-induced apoptosis is limited. One study showed that Egr-1 negatively regulates survivin expression and hence sensitises cell lines to TRAIL-induced apoptosis (Wagner et al, 2008). Another study linked Egr-1 to TRAIL that showed that TNF and TRAIL are released from irradiated (IR) tumour cells and induce bystander death of neighbouring/IR-unaffected cells. Although TNF secretion was mediated by Egr-1, TRAIL secretion only occurred in a tumour cells line that did not express functional Egr-1 (Shareef 

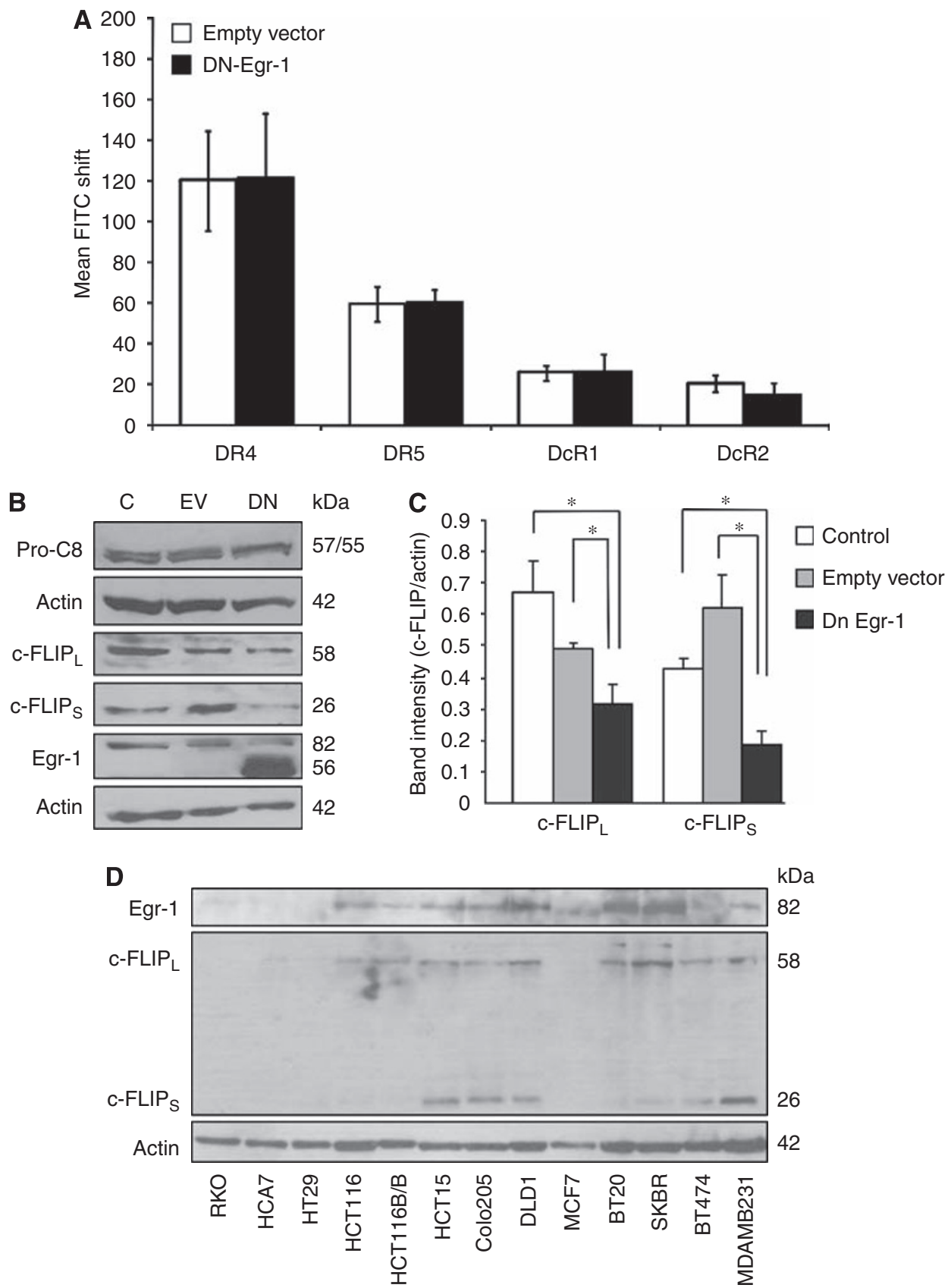

Figure 5 DN-Egr-I reduces c-FLIP expression in HCTI5 cells. (A) Effect of DN-Egr-I on the cell surface expression of TRAIL receptors. Mock- (EV) or DN-Egr-I (DN)-transfected HCTI5 cells were analysed for surface expression of DR4, DR5, DcRI and DcR2 at $48 \mathrm{~h}$ after transfection using flow cytometry. The graph shows the averaged geometric mean of histogram peaks corrected with isotype control of five independent experiments. (B) Effect of DN-Egr-I on pro-caspase-8 and c-FLIP expression. Lysates of untransfected (C), mock- (EV) or DN-Egr-I (DN)-transfected HCTI5 cells at $48 \mathrm{~h}$ after transfection were analysed for pro-caspase-8 protein expression using western blotting. The image represents two independent experiments. (C) Densitometric quantification of c-FLIPL and c-FLIPS blots using GeneTools software (version 3.07, SynGene, Cambridge, UK). c-FLIP expression values were normalised to actin expression level. Results are presented as mean \pm s.e.m. of three independent experiments, $* P<0.05$. (D) Expression of Egr-I and c-FLIP in colon and breast cancer cell lines. Cell lysates of untreated cells were prepared and analysed for the expression of Egr- I, c-FLIPL, c-FLIPS and $\beta$-actin using western blotting. The image is representative of two independent experiments.

et al, 2007). This study also indicates that during irradiation or genotoxic drug exposure, Egr-1 enhances tumour regression by inducing a bystander effect.

Our study found that Egr-1 is not only rapidly induced by TRAIL, but is also constitutively expressed at a relatively high level in many colon carcinoma cell lines. Another study also found Egr-1 upregulation at the mRNA level in early-onset colorectal cancers (Hong et al, 2007). Inhibition of Egr-1 by overexpressing DN-Egr-1 augmented cell death induced by TRAIL through the
DR5, but not through the DR4 receptor. The differential role of DR4 and DR5 may relate to our finding that in HCT15 cells DR4mediated apoptosis requires mitochondrial amplification whereas DR5 stimulation induces a type I, mitochondrial-independent apoptotic pathway. Inhibition of Egr-1 however did not alter expression of the Bcl-2 family members, Bax, Bcl-2, Bcl- $\mathrm{X}_{\mathrm{L}}$ or Mcl-1. In addition, other studies examining the regulation of Bcl-2 proteins by Egr-1 have shown induction of the pro-apoptotic member, Bax, and repression of Bcl-2, which would enhance the 
DR4-mediated, type II pathway, rather than the DR5-mediated type I pathway (Huang et al, 1998b; Ahmed, 2004; Zagurovskaya et al, 2009).

Inhibition of Egr-1 by a dominant-negative mutant, or siRNAmediated knockdown, significantly decreased the expression of the caspase- 8 inhibitor protein, c-FLIP, especially its short isoform (c-FLIP ${ }_{S}$ ) and Egr-1 expression associated with high c-FLIP expression in a number of cancer cell lines. The reduction in c-FLIP expression was only partial; however, this experiment probably underestimated the effect of Egr-1 on c-FLIP expression because the maximum transfection efficiency of DN-Egr-1 that we could achieve was $50 \%$ in HCT15 cells. Nonetheless, we cannot exclude the contribution of other Egr-1 regulated genes to TRAIL sensitivity.

\section{A}
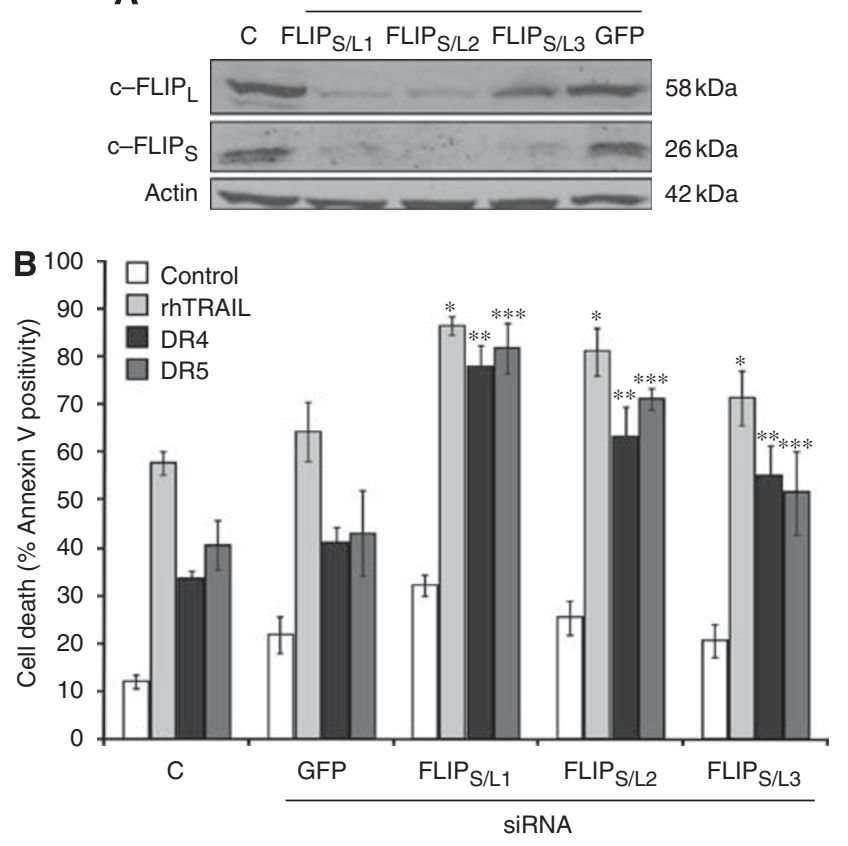

C
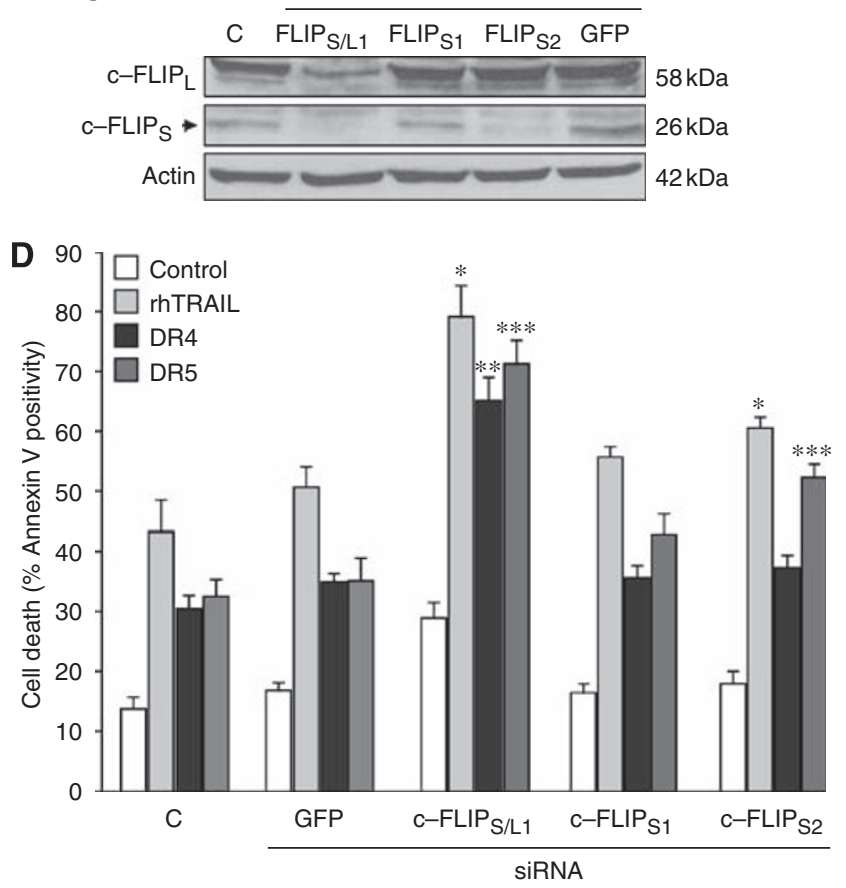

The $5^{\prime}$ region of the c-FLIP gene contains an Egr-1 binding site. Given that the Egr-1 binding site is a rare promoter element, and that the mouse c-FLIP promoter also contains an Egr-1 binding site (data not shown), it may be a bona fide site and thus indicate a direct regulation of c-FLIP by Egr-1; however, only experimental evidence can confirm it. The c-FLIP promoter also contains a number of AP-1 binding sites and c-Jun is known to be activated by DR4 and DR5. However, inhibition of c-Jun with a dominantnegative construct failed to alter TRAIL sensitivity (data not shown), indicating that c-Jun does not have a major role in regulating c-FLIP expression. Inhibition of Egr-1 affected c-FLIP expression more than of $c-$ FLIP $_{L}$ probably because of a differential degradation of c-FLIP isoforms. C-FLIP ${ }_{S}$ has been shown to be more prone to ubiquitylation and degradation than c-FLIP ${ }_{\mathrm{L}}$. Lysines 192 and 195 are principal ubiquitin acceptors in c-FLIP $S_{S}$ but not in $\mathrm{c}-\mathrm{FLIP}_{\mathrm{L}}$ because a 19 amino acid tail, which is specific to c-FLIP $_{S}$ and adjacent to the two target lysines, is required for correct positioning and subsequent ubiquitylation of the target lysines (Poukkula et al, 2005).

The considerable level of basal Egr-1 expression in colon carcinoma cells can maintain high c-FLIP expression levels, in particular c-FLIPs, and can thus reduce TRAIL sensitivity. Furthermore, upon DR4/DR5 stimulation Egr-1 becomes induced, which may further increase c-FLIP levels and protect the cells from

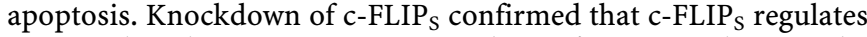
DR5-mediated apoptosis more so than of DR4, explaining the specific potentiating effect of DN-Egr-1 of DR5, but not of DR4induced cell death. This specific effect of c-FLIP either relates to its differential binding to DR4 vs DR5 or to its ability to block type I but not type II apoptosis. It is feasible that despite the presence of $c-F L I P$ on the DISC, some low level of pro-caspase- 8 processing can occur. This would allow the progression of the type II pathway, but would be insufficient to trigger the type I pathway. Inhibition of Egr-1 activity also increased apoptosis induction by other death receptors (TNFRI and Fas) known to be inhibited by c-FLIP. This also indicates that the effect of Egr-1 on c-FLIP expression has a significant biological effect.

In conclusion, this study shows that Egr-1 regulates the expression of c-FLIP in colon carcinoma cells and probably this mechanism contributes to Egr-1-mediated TRAIL resistance. Constitutive Egr-1 expression has been shown to correlate with prostate and gastric tumour aggressiveness and metastasis

Figure 6 Knockdown of c-FLIPS potentiates DR5-induced apoptosis in HCT5 cells. (A) Cell lysates were prepared from HCTI 5 cells transfected with three different siRNA constructs targeting the common region of $c-F L I P_{S}$ and $c-F L I P_{L}\left(c-F L I P_{S / L I-3}\right)$ or GFP as a negative control at $24 \mathrm{~h}$ after transfection and knockdown of c-FLIP $P_{L}$ and $c-F L I P_{S}$ were measured using western blot analysis. Actin expression was determined to serve as loading control. The image is representative of three independent experiments. (B) Simultaneous knockdown of c-FLIP and C-FLIPL potentiates TRAIL, DR4- and DR5-induced HCTI5 apoptosis. HCTI5 cells transfected as in (A) were treated at $24 \mathrm{~h}$ after transfection with $50 \mathrm{ng} \mathrm{ml}^{-1}$ rhTRAIL or I $0 \mathrm{nM}$ crosslinked agonistic DR4 (DR4) and DR5 (DR5) antibodies for $5 \mathrm{~h}$ and apoptosis was assessed using Annexin $\mathrm{V}$ staining. Results are presented as means \pm s.e.m. of three independent experiments; ${ }^{*} P<0.05$. (C) Selective knockdown of c-FLIPs. Cell lysates were prepared from HCTI 5 cells transfected with two different siRNA constructs targeting the exon 7 in c-FLIP $\left(c-F L I P_{S I}, 2\right)$ or GFP as a negative control at $24 \mathrm{~h}$ after transfection and knockdown of $\mathrm{C}-\mathrm{FLIP} \mathrm{P}_{\mathrm{L}}$ and $\mathrm{c}-\mathrm{FLIP}$ S were measured using western blot analysis. Actin expression was determined to serve as loading control. The image is representative of three independent experiments. (D) Selective knockdown of c-FLIPS potentiates DR5-, but not DR4induced HCTI 5 apoptosis. HCTI 5 cells transfected as in (C) were treated as in (B) and apoptosis was assessed using Annexin $\vee$ staining. Results are presented as means \pm s.e.m. of three independent experiments; $* P<0.05$ Asterisks (*) label samples with significant difference from the TRAILtreated (*), DR4-treated (**) or DR5-treated (***) GFP-transfected sample $(P<0.05)$. 
(Thigpen et al, 1996; Kobayashi et al, 2002). Recent results at the same time indicate that loss of TRAIL sensitivity of tumour cells is a key step enabling metastasis (Grosse-Wilde et al, 2008). The results of our study may shed light on the connection between Egr-1 expression and tumour aggressiveness. Our findings also indicate that the function of DR4 and DR5 is regulated separately intracellularly and the Egr-1 status of a tumour may indicate the sensitivity of the tumour towards death receptor agonist therapeutics.

\section{ACKNOWLEDGEMENTS}

This work is supported by Cancer Research Ireland and Millennium Grant NUI Galway. The dominant-negative Egr-1

\section{REFERENCES}

Abdulkadir SA, Qu Z, Garabedian E, Song SK, Peters TJ, Svaren J, Carbone JM, Naughton CK, Catalona WJ, Ackerman JJ, Gordon JI, Humphrey PA, Milbrandt J (2001) Impaired prostate tumorigenesis in Egr1-deficient mice. Nat Med 7: $101-107$

Ahmed MM (2004) Regulation of radiation-induced apoptosis by early growth response-1 gene in solid tumors. Curr Cancer Drug Targets 4: $43-52$

Al-Sarraj A, Day RM, Thiel G (2005) Specificity of transcriptional regulation by the zinc finger transcription factors Sp1, Sp3, and Egr-1. $J$ Cell Biochem 94: 153-167

Ashkenazi A (2002) Targeting death and decoy receptors of the tumournecrosis factor superfamily. Nat Rev Cancer 2: 420-430

Ashkenazi A (2008) Targeting the extrinsic apoptosis pathway in cancer. Cytokine Growth Factor Rev 19: 325 - 331

Ashkenazi A, Dixit VM (1998) Death receptors: signaling and modulation. Science 281: $1305-1308$

Ashkenazi A, Holland P, Eckhardt SG (2008) Ligand-based targeting of apoptosis in cancer: the potential of recombinant human apoptosis ligand 2/tumor necrosis factor-related apoptosis-inducing ligand (rhApo2L/TRAIL). J Clin Oncol 26: 3621-3630

Barnhart BC, Alappat EC, Peter ME (2003) The CD95 type I/type II model. Semin Immunol 15: 185-193

Beckmann AM, Wilce PA (1997) Egr transcription factors in the nervous system. Neurochem Int 31: 477-510; discussion 517-6

Clancy L, Mruk K, Archer K, Woelfel M, Mongkolsapaya J, Screaton G, Lenardo MJ, Chan FK (2005) Preligand assembly domain-mediated ligand-independent association between TRAIL receptor 4 (TR4) and TR2 regulates TRAIL-induced apoptosis. Proc Natl Acad Sci USA 102: $18099-18104$

Di Pietro R, Zauli G (2004) Emerging non-apoptotic functions of tumor necrosis factor-related apoptosis-inducing ligand (TRAIL)/Apo2L. J Cell Physiol 201: $331-340$

Duiker EW, Mom CH, de Jong S, Willemse PH, Gietema JA, van der Zee AG, de Vries EG (2006) The clinical trail of TRAIL. Eur J Cancer 42: $2233-2240$

Eid MA, Kumar MV, Iczkowski KA, Bostwick DG, Tindall DJ (1998) Expression of early growth response genes in human prostate cancer. Cancer Res 58: $2461-2468$

Eskes R, Desagher S, Antonsson B, Martinou JC (2000) Bid induces the oligomerization and insertion of $\mathrm{Bax}$ into the outer mitochondrial membrane. Mol Cell Biol 20: 929-935

Falschlehner C, Emmerich CH, Gerlach B, Walczak H (2007) TRAIL signalling: decisions between life and death. Int J Biochem Cell Biol 39: $1462-1475$

Fulda S, Meyer E, Debatin KM (2002) Inhibition of TRAIL-induced apoptosis by Bcl-2 overexpression. Oncogene 21: 2283-2294

Golks A, Brenner D, Fritsch C, Krammer PH, Lavrik IN (2005) c-FLIPR, a new regulator of death receptor-induced apoptosis. J Biol Chem 280: $14507-14513$

Green DR (2000) Apoptotic pathways: paper wraps stone blunts scissors. Cell 102: $1-4$

Green DR, Kroemer G (2004) The pathophysiology of mitochondrial cell death. Science 305: 626-629 construct was a generous gift from Professor Gerald Thiel (University of Saarland Medical Center, Homburg, Germany) and the mitochondrion-localised Bcl-2 construct from Dr Peter Daniel (University of Berlin). We thank Aoife O'Reilly for her technical help.

\section{Conflict of interest}

Professor Afshin Samali is a founding member of the company, Triskel Therapeutics Ltd.

Supplementary Information accompanies the paper on British Journal of Cancer website (http://www.nature.com/bjc)
Grosse-Wilde A, Voloshanenko O, Bailey SL, Longton GM, Schaefer U, Csernok AI, Schutz G, Greiner EF, Kemp CJ, Walczak H (2008) TRAIL-R deficiency in mice enhances lymph node metastasis without affecting primary tumor development. J Clin Invest 118: $100-110$

Hong Y, Ho KS, Eu KW, Cheah PY (2007) A susceptibility gene set for early onset colorectal cancer that integrates diverse signaling pathways: implication for tumorigenesis. Clin Cancer Res 13: 1107-1114

Huang RP, Fan Y, deBelle I, Ni Z, Matheny W, Adamson ED (1998a) Egr-1 inhibits apoptosis during the UV response: correlation of cell survival with Egr-1 phosphorylation. Cell Death Differ 5: 96-106

Huang RP, Fan Y, Peng A, Zeng ZL, Reed JC, Adamson ED, Boynton AL (1998b) Suppression of human fibrosarcoma cell growth by transcription factor, Egr-1, involves down-regulation of Bcl-2. Int J Cancer 77: 880-886

Ichikawa K, Liu W, Zhao L, Wang Z, Liu D, Ohtsuka T, Zhang H, Mountz JD, Koopman WJ, Kimberly RP, Zhou T (2001) Tumoricidal activity of a novel anti-human DR5 monoclonal antibody without hepatocyte cytotoxicity. Nat Med 7: 954-960

Kelley RF, Totpal K, Lindstrom SH, Mathieu M, Billeci K, Deforge L, Pai R, Hymowitz SG, Ashkenazi A (2005) Receptor-selective mutants of apoptosis-inducing ligand 2/tumor necrosis factor-related apoptosisinducing ligand reveal a greater contribution of death receptor (DR) 5 than DR4 to apoptosis signaling. J Biol Chem 280: 2205-2212

Kischkel FC, Lawrence DA, Chuntharapai A, Schow P, Kim KJ, Ashkenazi A (2000) Apo2L/TRAIL-dependent recruitment of endogenous FADD and caspase- 8 to death receptors 4 and 5. Immunity 12: 611-620

Kobayashi D, Yamada M, Kamagata C, Kaneko R, Tsuji N, Nakamura M, Yagihashi A, Watanabe N (2002) Overexpression of early growth response-1 as a metastasis-regulatory factor in gastric cancer. Anticancer Res 22: $3963-3970$

Kumar-Sinha C, Varambally S, Sreekumar A, Chinnaiyan AM (2002) Molecular cross-talk between the TRAIL and interferon signaling pathways. J Biol Chem 277: 575-585

Longley DB, Wilson TR, McEwan M, Allen WL, McDermott U, Galligan L, Johnston PG (2006) c-FLIP inhibits chemotherapy-induced colorectal cancer cell death. Oncogene 25: 838-848

MacFarlane M, Inoue S, Kohlhaas SL, Majid A, Harper N, Kennedy DB, Dyer MJ, Cohen GM (2005) Chronic lymphocytic leukemic cells exhibit apoptotic signaling via TRAIL-R1. Cell Death Differ 12: 773-782

Mahalingam D, Szegezdi E, Keane M, Jong SD, Samali A (2009) TRAIL receptor signalling and modulation: are we on the right TRAIL? Cancer Treat Rev 35(3): 280-288

Merino D, Lalaoui N, Morizot A, Schneider P, Solary E, Micheau O (2006) Differential inhibition of TRAIL-mediated DR5-DISC formation by decoy receptors 1 and 2. Mol Cell Biol 26: 7046-7055

Nakajima A, Kojima Y, Nakayama M, Yagita H, Okumura K, Nakano H (2008) Downregulation of c-FLIP promotes caspase-dependent JNK activation and reactive oxygen species accumulation in tumor cells. Oncogene 27: $76-84$

Papenfuss K, Cordier SM, Walczak H (2008) Death receptors as targets for anti-cancer therapy. J Cell Mol Med 12: 2566-2585

Poukkula M, Kaunisto A, Hietakangas V, Denessiouk K, Katajamaki T, Johnson MS, Sistonen L, Eriksson JE (2005) Rapid turnover of c-FLIPshort is determined by its unique C-terminal tail. J Biol Chem 280: 27345-27355 
Egr-I regulates DR5-induced apoptosis via c-FLIP

D Mahalingam et al

764

Riggs PK, Rho O, DiGiovanni J (2000) Alteration of Egr-1 mRNA during multistage carcinogenesis in mouse skin. Mol Carcinog 27: 247-251

Scaffidi C, Schmitz I, Zha J, Korsmeyer SJ, Krammer PH, Peter ME (1999) Differential modulation of apoptosis sensitivity in CD95 type I and type II cells. J Biol Chem 274: 22532-22538

Schug J (2008) Using TESS to predict transcription factor binding sites in DNA sequence. Curr Protoc Bioinformatics Chapter 2, Unit 2.6

Scott FL, Stec B, Pop C, Dobaczewska MK, Lee JJ, Monosov E, Robinson H, Salvesen GS, Schwarzenbacher R, Riedl SJ (2009) The Fas-FADD death domain complex structure unravels signalling by receptor clustering Nature 457: 1019-1022

Shareef MM, Cui N, Burikhanov R, Gupta S, Satishkumar S, Shajahan S, Mohiuddin M, Rangnekar VM, Ahmed MM (2007) Role of tumor necrosis factor-alpha and TRAIL in high-dose radiation-induced bystander signaling in lung adenocarcinoma. Cancer Res 67: $11811-11820$

Sprick MR, Weigand MA, Rieser E, Rauch CT, Juo P, Blenis J, Krammer PH, Walczak H (2000) FADD/MORT1 and caspase-8 are recruited to TRAIL receptors 1 and 2 and are essential for apoptosis mediated by TRAIL receptor 2. Immunity 12: 599-609

Swirnoff A, Milbrandt J (1995) DNA-binding specificity of NGFI-A and related zinc finger transcription factors. Mol Cell Biol 15: $2275-2287$

Szegezdi E, Herbert KR, Kavanagh ET, Samali A, Gorman AM (2008) Nerve growth factor blocks thapsigargin-induced apoptosis at the level of the mitochondrion via regulation of Bim. J Cell Mol Med 12: 2482-2496
Thiel G, Cibelli G (2002) Regulation of life and death by the zinc finger transcription factor Egr-1. J Cell Physiol 193: 287-292

Thigpen AE, Cala KM, Guileyardo JM, Molberg KH, McConnell JD, Russell DW (1996) Increased expression of early growth response-1 messenger ribonucleic acid in prostatic adenocarcinoma. J Urol 155: 975-981

van der Sloot AM, Tur V, Szegezdi E, Mullally MM, Cool RH, Samali A, Serrano L, Quax WJ (2006) Designed tumor necrosis factor-related apoptosis-inducing ligand variants initiating apoptosis exclusively via the DR5 receptor. Proc Natl Acad Sci USA 103: 8634-8639

van Geelen CM, de Vries EG, Le TK, van Weeghel RP, de Jong S (2003) Differential modulation of the TRAIL receptors and the CD95 receptor in colon carcinoma cell lines. Br J Cancer 89: 363-373

Virolle T, Adamson ED, Baron V, Birle D, Mercola D, Mustelin T, de Belle I (2001) The Egr-1 transcription factor directly activates PTEN during irradiation-induced signalling. Nat Cell Biol 3: $1124-1128$

Wagner M, Schmelz K, Dorken B, Tamm I (2008) Transcriptional regulation of human survivin by early growth response (Egr)-1 transcription factor. Int J Cancer 122: $1278-1287$

Zagurovskaya M, Shareef MM, Das A, Reeves A, Gupta S, Sudol M, Bedford MT, Prichard J, Mohiuddin M, Ahmed MM (2009) EGR-1 forms a complex with YAP-1 and upregulates Bax expression in irradiated prostate carcinoma cells. Oncogene 28: 1121-1131

Zhang X, Jin TG, Yang H, DeWolf WC, Khosravi-Far R, Olumi AF (2004) Persistent c-FLIP(L) expression is necessary and sufficient to maintain resistance to tumor necrosis factor-related apoptosis-inducing ligandmediated apoptosis in prostate cancer. Cancer Res 64: 7086-7091 